\title{
Retinal angiomatous proliferation associated with risk alleles of ARMS2/HTRA I gene polymorphisms in Japanese patients
}

This article was published in the following Dove Press journal:

Clinical Ophthalmology

27 December 2013

Number of times this article has been viewed

\author{
Yasuhiro Ohkuma' \\ Takaaki Hayashi' \\ Tsutomu Sakai' \\ Akira Watanabe' \\ Hisashi Yamada ${ }^{2}$ \\ Masakazu Akahori ${ }^{3}$ \\ Takeshi Itabashi ${ }^{3}$ \\ Takeshi Iwata ${ }^{3}$ \\ Toru Noda ${ }^{4}$ \\ Hiroshi Tsuneoka' \\ 'Department of Ophthalmology, \\ ${ }^{2}$ Department of Molecular Genetics, \\ Institute of DNA Medicine, The \\ Jikei University School of Medicine, \\ ${ }^{3}$ Division of Molecular and Cellular \\ Biology, National Institute of Sensory \\ Organs, ${ }^{4}$ Division of Ophthalmology, \\ National Hospital Organization Tokyo \\ Medical Center, Tokyo, Japan
}

Background: The purpose of this study was to investigate the association between ARMS2/ HTRA1, $C F H$, and $C 3$ gene polymorphisms and retinal angiomatous proliferation (RAP), an infrequent and severe form of exudative age-related macular degeneration, which is characterized by intraretinal neovascularization.

Methods: Diagnosis of RAP was based on fundus photographs, images of fluorescein and indocyanine green angiographies, and optical coherence tomography findings. Six single nucleotide polymorphisms (SNPs), A69S (rs10490924) in ARMS2, rs1 1200638 in HTRA1, I62V (rs800292) in $C F H, Y 402 \mathrm{H}$ (rs1061170) in CFH, R80G (rs2230199) in C3, and rs2241394 in $C 3$, were genotyped in eight Japanese patients with RAP.

Results: The two SNPs in the ARMS2/HTRA1 were in complete linkage disequilibrium. The frequency of the risk T allele in ARMS2 (the risk A allele in HTRA1) was 93.8\% in the RAP patients. The frequency of homozygosity for the risk genotype TT of ARMS2 (the risk genotype AA of HTRA1) was $87.5 \%$. The frequency of the non-risk allele (A) of I62V was $100 \%$. The frequencies of risk alleles of $\mathrm{Y} 402 \mathrm{H}, \mathrm{R} 80 \mathrm{G}$, and $\mathrm{rs} 2241394$ were $12.5 \%, 0 \%$, and $18.8 \%$, respectively.

Conclusion: Our results suggest that the risk alleles of the ARMS2/HTRA1 SNPs may be associated with development of RAP and play a major role in the pathogenesis of intraretinal angiogenesis.

Keywords: age-related macular degeneration, retinal angiomatous proliferation, single nucleotide polymorphisms, ARMS2/HTRA1 genes, components of the complement system

\section{Introduction}

Age-related macular degeneration (AMD) is the most common cause of legal blindness in the elderly, affecting more than 50 million people worldwide. ${ }^{1}$ In Japan, the prevalence of AMD has risen from $0.87 \%$ in 1988 to $1.4 \%$ in 2007.,3 Maruko et al have classified exudative AMD patients into three subtypes, namely typical wet-type AMD, polypoidal choroidal vasculopathy (PCV), and retinal angiomatous proliferation (RAP). ${ }^{4}$

AMD is a multifactorial disease with genetic, behavioral, and environmental factors. ${ }^{5}$ Recently, genetic association studies have revealed that single nucleotide polymorphisms (SNPs) in CFH (1q32), ARMS2/HTRA1 (10q26), and C3 (19p13) have been identified as major contributors to the pathogenesis of AMD. ${ }^{6-17}$ Among various SNPs of those genes, the Y402H (rs1061170) and I62V (rs800292) variants in the CFH gene and the A69S (rs10490924) variant in the ARMS2 gene have been investigated in detail. ${ }^{6-15,18-27}$ The differences in genotypes associated with AMD
Correspondence: Takaaki Hayashi Department of Ophthalmology, The Jikei University School of Medicine, 3-25-8 Nishi-shimbashi, Minato-ku, Tokyo 105-846I, Japan Tel +8 I 33433 IIII ext 358 I

Fax +8I 334331936

Email taka@jikei.ac.jp 
have been investigated among various ethnic groups and by subtypes of exudative AMD, ${ }^{16,18-27}$ showing that the I62V and A69S variants are associated with AMD in both Caucasian and Asian subjects. ${ }^{18-27}$ The Y402H and R80G (in the $C 3$ gene) variants have been associated with AMD in Caucasians ${ }^{6-15}$ but not in Asians. ${ }^{18,19,21-25,28}$ The $\mathrm{C}$ allele of the $\mathrm{Y} 402 \mathrm{H}$ variant and the $\mathrm{G}$ allele of the $\mathrm{R} 80 \mathrm{G}$ variant are infrequent in Asians.

The term RAP was first coined by Yannuzzi et al in $2001 .^{29}$ They suggested the retinal origin of this neovascularization, which proceeds posteriorly and finally forms a retinal-choroidal anastomosis. RAP is sometimes called type 3 neovascularization to distinguish it from type 1 neovascularization (choroidal neovascularization under the retinal pigment epithelium) and type 2 neovascularization (choroidal neovascularization that penetrates the retinal pigment epithelium). ${ }^{30,31}$ RAP accounts for $4.5 \%$ of all exudative AMD in Japanese patients ${ }^{4}$ and $15 \%$ of exudative AMD in Caucasian patients. ${ }^{32}$ RAP is characterized by bilateral, multiple soft drusen, intraretinal hemorrhages, and intraretinal edema. The natural history of RAP is characterized by a rapid loss of vision. ${ }^{33}$ RAP resists various treatments and recurs persistently. ${ }^{34-40}$

The phenotypic diversity of AMD is thought to be related to differences in genetic backgrounds. ${ }^{20,24-27}$ Various reports have examined genetic backgrounds in PCV. Lee et al reported that the $\mathrm{I} 62 \mathrm{~V}$ and $\mathrm{A} 69 \mathrm{~S}$ variants, but not the $\mathrm{Y} 402 \mathrm{H}$ variant, were related to $\mathrm{PCV}$ in Chinese patients. ${ }^{23}$ Hayashi et al reported that all three of these SNPs (I62V, Y402H, and A69S) were related to PCV in Japanese patients. ${ }^{26}$ Goto et al reported that rs2241394 in the $C 3$ gene was associated with PCV. ${ }^{25}$

Wegscheider et al reported that the $\mathrm{Y} 402 \mathrm{H}$ polymorphism was associated with RAP in Caucasians. ${ }^{20}$ However, the genetic association with RAP has not been evaluated sufficiently because of the rarity of RAP in Japan. There are only a few reports about associations between A69S and RAP in the Japanese population. ${ }^{26,27}$ The purpose of the current study was to investigate the involvement of genetic factors in not only the ARMS2/HTRA1 but also the $C F H$ and $C 3$ genes in Japanese patients with RAP.

\section{Materials and methods}

The study was approved by the institutional review board of The Jikei Medical University, and all procedures were conducted in accordance with the principles of the Declaration of Helsinki. Eight unrelated Japanese patients with RAP were recruited from the Department of Ophthalmology at
The Jikei Medical University and the National Hospital Organization Tokyo Medical Center. Informed consent was obtained from all subjects.

All patients with RAP underwent a full ophthalmic examination, including slit-lamp biomicroscopy, funduscopy, optical coherence tomography, and fluorescein and indocyanine green fundus angiographies. The diagnosis of RAP was based on the criteria of Yannuzzi et $\mathrm{al}^{29}$ and was classified as a defined anastomosis connecting the retinal circulation to a vascular complex within the retina, usually with surrounding intraretinal blood and intraretinal or cystoid macular edema.

Genomic DNA was extracted from the peripheral blood of each individual. A total of six SNPs consisting of A69S (rs10490924) in ARMS2, rs11200638 in HTRA1, Y402H (rs1061170) in CFH, I62V (rs800292) in $C F H$, R80G (rs2230199) in C3, and rs2241394 in $C 3$ were genotyped. Polymerase chain reaction amplification was performed using LA Taq polymerase (Takara Bio Inc, Ohtsu, Japan) and primers for ARMS2 (forward primer: 5'-GCCTATACCCAGGACCGATG-3', reverse primer: 5'-CATGTTCTCAGCATCTCCAAGTC-3'), HTRA 1 (forward primer: 5'-TCTCTGCGAATACGGACACG-3', reverse primer: 5'-ACT GTG TCCATT CAG CTC CTA A-3'), CFH Y402H (forward primer: 5'-CAGAAATAGGGCCAAGAAAAGAGT-3', reverse primer: 5'-ATGTAACTGTGGTCTGCGC-3'), CFH I62V (forward primer: 5'-GATTGCAATGAACTTCCTCCAAG-3', reverse primer:5'-GGAT TAAGAGCA ACC CATTCTCC-3'), C3 R80G (forward primer: 5'-CCTCGCACCTCCTTCACA-3', reverse primer: 5'-TCTGGCTGGCACCTCAAT-3'), and C3 rs2241394 (forward primer: 5'-GGCTGGGTGACTGTACCTCTTC-3', reverse primer: 5'-CATGTTCTCAGCATCTCCAAGTC-3') to amplify these regions. Polymerase chain reaction products were used as the templates for direct DNA sequencing kits (Applied Biosystems, Foster City, CA, USA) on an automated sequencer (3730xl DNA analyzer; Applied Biosystems).

\section{Results}

\section{Genetic analysis}

Five men and three women were analyzed in the study. The mean patient age was 82.6 \pm 4.6 years (range 76-91 years). Both eyes were affected in four patients (50.0\%). All SNPs were successfully genotyped in all patients (Table 1). The two SNPs in the ARMS2/HTRA1 were in complete linkage disequilibrium. The frequency of the risk $\mathrm{T}$ allele in 
Table I Polymorphisms in ARMS2/HTRA //CFH/C3 genes: genotypes in Japanese patients with retinal angiomatous proliferation

\begin{tabular}{|c|c|c|c|c|c|c|c|c|c|}
\hline \multirow{2}{*}{$\begin{array}{l}\text { Patient } \\
\text { number }\end{array}$} & \multirow[t]{2}{*}{ Age } & \multirow[t]{2}{*}{ Sex } & \multirow{2}{*}{$\begin{array}{l}\text { Affected } \\
\text { eye }\end{array}$} & \multirow{2}{*}{$\begin{array}{l}\text { ARMS2 } \\
\text { rs I 0490924 } \\
\text { (A69S) }\end{array}$} & \multirow{2}{*}{$\frac{\text { HTRAI }}{\text { rs I I } 20638}$} & \multicolumn{2}{|l|}{$\mathrm{CFH}$} & \multicolumn{2}{|l|}{ C3 } \\
\hline & & & & & & $\begin{array}{l}\text { rs800292 } \\
(\mathrm{I} 62 \mathrm{~V})\end{array}$ & $\begin{array}{l}\text { rsI06II } 70 \\
(\mathrm{Y402H})\end{array}$ & $\begin{array}{l}\text { rs2230I99 } \\
\text { (R80G) }\end{array}$ & rs2241394 \\
\hline I & 83 & $\mathrm{~F}$ & Bilateral & TT & AA & AA & $\mathrm{TT}$ & $\mathrm{CC}$ & CG \\
\hline 2 & 79 & $M$ & Unilateral & TT & AA & AA & CT & $\mathrm{CC}$ & $\mathrm{CC}$ \\
\hline 3 & 84 & $M$ & Unilateral & TT & AA & $\mathrm{AA}$ & $\mathrm{TT}$ & $\mathrm{CC}$ & $\mathrm{CC}$ \\
\hline 4 & 87 & $\mathrm{~F}$ & Unilateral & TT & AA & $\mathrm{AA}$ & CT & $\mathrm{CC}$ & CG \\
\hline 5 & 82 & $M$ & Bilateral & TT & AA & AA & $\mathrm{TT}$ & $\mathrm{CC}$ & $\mathrm{CC}$ \\
\hline 6 & 78 & $M$ & Unilateral & TT & AA & AA & TT & $\mathrm{CC}$ & $\mathrm{CC}$ \\
\hline 7 & 76 & $\mathrm{~F}$ & Bilateral & TT & AA & AA & TT & $\mathrm{CC}$ & CG \\
\hline 8 & 91 & $M$ & Bilateral & TG & AG & AA & TT & $\mathrm{CC}$ & $\mathrm{CC}$ \\
\hline
\end{tabular}

Note: Risk alleles are shown in bold.

Abbreviations: $M$, male; F, female.

the ARMS2 gene (the risk A allele in the HTRA1 gene) was $93.8 \%$. The frequency of homozygosity for the risk genotype (TT) of the ARMS2 gene was $87.5 \%$. The frequency of the non-risk allele (A) of $\mathrm{I} 62 \mathrm{~V}$ was $100 \%$. The frequencies of risk alleles of $\mathrm{Y} 402 \mathrm{H}$ in the $\mathrm{CFH}$ gene, rs2230199 (R80G) and rs2241394 in the $C 3$ gene were $12.5 \%, 0 \%$, and $18.8 \%$, respectively.

\section{Representative case (patient I)}

An 83-year-old woman with homozygosity for the risk genotype (TT) of the ARMS2 gene presented with bilateral RAP (Figure 1). She had undergone cataract surgery in both eyes prior to diagnosis of RAP. Her decimal best-corrected visual acuity was 0.3 in the right eye and 0.07 in the left eye. Both eyes were treated by standard-fluence photodynamic therapy with verteporfin (Visudyne ${ }^{\circledR}$, Novartis Pharma AG, Basel, Switzerland $)$ in combination with $1.25 \mathrm{mg}(0.05 \mathrm{~mL})$ of intravitreal bevacizumab (Avastin ${ }^{\circledR}$, Genentech, San Francisco, CA, USA), and her vision improved to 0.5 in the right eye

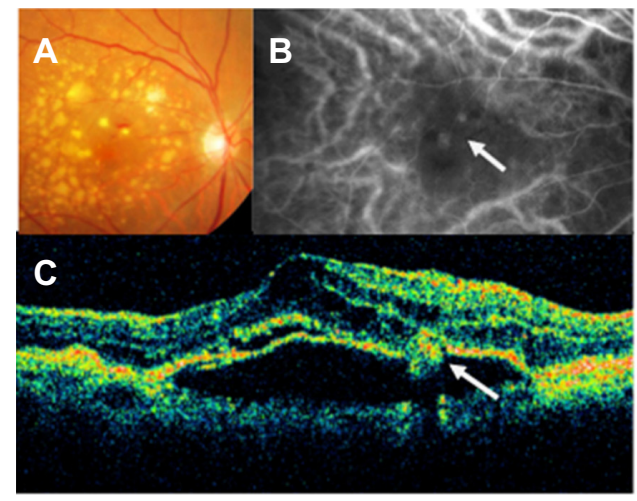

and 0.15 in the left eye, with a rapid resolution of intraretinal edema. There was no recurrence of intraretinal edema or hemorrhages, and her vision remained stable for 2 years following the combination therapy.

\section{Discussion}

In this study we genotyped six SNPs in RAP patients that were highly representative of the common genetic variations of exudative AMD. Our results raise the possibility of an association between ARMS2 (A69S)/HTRA1 (rs1120638) variants and RAP, but a weak association for the other SNPs. Hayashi et al recently demonstrated that the A69S, Y402H, and $\mathrm{I} 62 \mathrm{~V}$ variants are associated with RAP and that the A69S variant has the strongest association for RAP among the three exudative AMD subtypes. ${ }^{26}$ Tanaka et al also reported that A69S might serve as strong genetic markers of RAP. ${ }^{27}$ Our findings are consistent with their findings ${ }^{26,27}$ regarding the A69S variant, but we had negative results for the $\mathrm{I} 62 \mathrm{~V}(\mathrm{CFH})$ variant (Table 2).

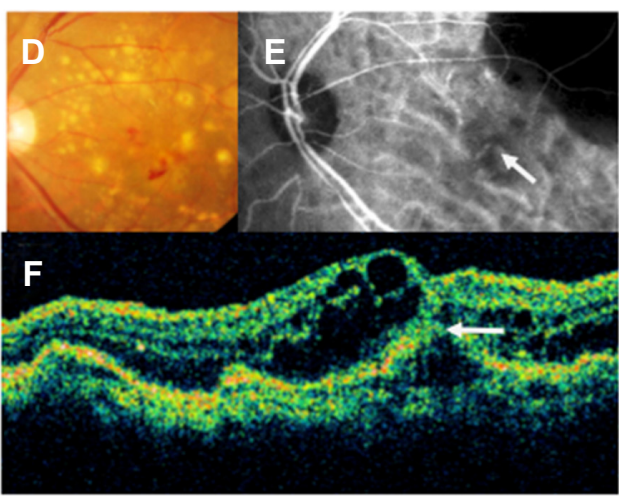

Figure I Color fundus photographs (A and $\mathbf{D}$ ), indocyanine green fundus angiographies (B and $\mathbf{E})$, and optical coherence tomography images (C and $\mathbf{F}$ ) from the right eye (A-C) and the left eye (D-F) of an 83-year-old woman (patient I).

Notes: We diagnosed her right eye with stage II retinal angiomatous proliferation and her left eye with stage III retinal angiomatous proliferation. (A and D) Fundus image shows intraretinal hemorrhages with a large number of soft drusen and pigment epithelial detachment. (B) Indocyanine green fundus angiographies shows some hotspots. One of them connects retinal vessels (arrow), corresponding to the intraretinal neovascularization. (C) A vertical optical coherence tomography image shows a pigment epithelial detachment, cystoid macular edema, and retinal angiomatous proliferation lesion (arrow). (E) Indocyanine green fundus angiographies shows choroidal neovascularization (arrow) that connects retinal vessels, corresponding to retinal-choroidal anastomosis. (F) A vertical optical coherence tomography image shows a pigment epithelial detachment, cystoid macular edema, and a retinal pigment epithelium line that has ruptured (arrow). 
Table 2 Genotype frequency of A69S (ARMS2), I62V (CFH), and Y402H (CFH) polymorphisms in Japanese controls and Japanese patients with retinal angiomatous proliferation

\begin{tabular}{|c|c|c|c|c|c|c|c|c|c|}
\hline \multirow[t]{2}{*}{ Genotype } & \multicolumn{3}{|c|}{ rs I 0490924 (A69S) } & \multicolumn{3}{|c|}{ rs800292 (162V) } & \multicolumn{3}{|c|}{ rs I $061170(Y 402 H)$} \\
\hline & TT & TG & GG & GG & GA & AA & $\mathrm{CC}$ & CT & TT \\
\hline Controls $(n=I, 35 I)^{26}$ & $196(14.6 \%)$ & $638(47.8 \%)$ & $502(37.6 \%)$ & $456(34.1 \%)$ & 649 (48.5\%) & $233(17.4 \%)$ & $8(0.6 \%)$ & $160(11.9 \%)$ & I, 174 (87.5\%) \\
\hline Patients $(n=36)^{26}$ & 31 (86.1\%) & $3(8.3 \%)$ & $2(5.6 \%)$ & $20(55.6 \%)$ & II (30.6\%) & $5(13.8 \%)$ & $0(0 \%)$ & $5(14.3 \%)$ & $30(85.7 \%)$ \\
\hline Patients $(n=5 I)^{27}$ & 39 (76.5\%) & $10(19.6 \%)$ & $2(3.9 \%)$ & $29(56.9 \%)$ & $20(39.2 \%)$ & $2(3.9 \%)$ & ND & ND & ND \\
\hline $\begin{array}{l}\text { Patients ( } n=8 \text { ) } \\
\text { (in present study) }\end{array}$ & 7 (87.5\%) & I (I2.5\%) & $0(0 \%)$ & $0(0 \%)$ & $0(0 \%)$ & $8(100 \%)$ & $0(0 \%)$ & $2(25 \%)$ & $6(75 \%)$ \\
\hline
\end{tabular}

Note: Risk alleles are shown in bold.

Abbreviation: ND, not described.

Components of the complement system have been identified in drusen, indicating a potential role of the complement system in the pathogenesis of AMD. ${ }^{41,42} \mathrm{C} 3$ and $\mathrm{CFH}$ are key components of the alternative complement pathway. $\mathrm{C} 3$ is the most abundant complement component and is synthesized predominantly in the liver. Cleavage of $\mathrm{C} 3$ into $\mathrm{C} 3 \mathrm{a}$ and $\mathrm{C} 3 \mathrm{~b}$ is the central step in complement activation and can be initiated by the classic antibodymediated pathway, the lectin pathway, or the alternative complement pathway. CFH is a critical negative regulator of the alternative pathway of the complement system. It binds to $\mathrm{C} 3 \mathrm{~b}$, promotes the decay of $\mathrm{C} 3$ convertase, and serves as a cofactor for the factor I-mediated proteolytic inactivation of $\mathrm{C} 3 \mathrm{~b}$, resulting in inhibition of the complement cascade.

Because there are bilateral multiple soft drusen in the presence in RAP, we suspected that RAP would be more strongly associated with genetic abnormalities in the complement system than other AMD subtypes. However, we hardly detected the risk alleles of the $\mathrm{CFH}$ and $\mathrm{C} 3$ genes. One reason for these results is the infrequency of the $\mathrm{C}$ allele in $\mathrm{Y} 402 \mathrm{H}$ and the $\mathrm{G}$ allele in R80G in Asians. Reticular pseudodrusen (RPD) are defined as "drusen that form ill-defined networks of broad interlacing ribbons" in the Wisconsin grading system for maculopathy. ${ }^{43}$ RPD have been recognized as a distinctive morphologic feature observed in exudative AMD. ${ }^{44}$ Recent studies have demonstrated the association between RPD and reduced macular sensitivity. ${ }^{45,46}$ Importantly, it is reported that the prevalence of RPD was high in patients with RAP and the risk genotype (TT) in A69S, ${ }^{47}$ and RPD usually occurs bilaterally, ${ }^{48}$ suggesting the impact of genetic background for RPD.

It was an unexpected result that we did not detect the risk $\mathrm{G}$ allele in I62V (Table 2). The I62V variant has been associated with exudative AMD in both Caucasian and Asian patients. ${ }^{18,19,21-25,27}$ In Japanese population samples, it has been demonstrated that the risk genotype (GG) in I62V is significantly associated with RAP (Table 2) ${ }^{26,27}$ However, the risk genotype in $\mathrm{I} 62 \mathrm{~V}$ was not detected in our RAP patients (Table 2). Our findings suggest that the presence of the risk genotype (I62V) may not be necessarily associated with development of RAP. A larger sample size will be required to determine whether the risk genotype in $\mathrm{I} 62 \mathrm{~V}$ is eventually associated with RAP.

RAP is characterized by intraretinal neovascularization above the retinal pigment epithelium. Two different origins of this neovascularization have been proposed. Yannuzzi et al suggested that the neovascularization in RAP originates from the neural retina. ${ }^{29}$ On the other hand, Freund et al proposed type 3 neovascularization that originates not only from deep retinal capillaries but also from the choroid. ${ }^{31}$ As for the location of gene expression, the $C F H$ gene is expressed primarily in the retinal pigment epithelium, drusen, and choroidal capillaries; ${ }^{6}$ the $C 3$ gene is expressed in the neural retina, choroid, and retinal pigment epithelium ${ }^{41}$ and the $A R M S 2$ gene is expressed in the ellipsoid region of the photoreceptor cells. ${ }^{14}$ Since it seems that the location of characteristic neovascularization corresponds to the location of susceptible gene expression in RAP, our results support the hypothesis by Yannuzzi et $\mathrm{al}^{29}$ that the origin of neovascularization in RAP is in the neural retina.

In conclusion, our results suggest that the risk alleles/ genotypes of the ARMS2/HTRA1 SNPs may be strongly associated with development of RAP and that they play a major role in the pathogenesis of intraretinal angiogenesis.

\section{Acknowledgments}

This work was supported by grants from The Jikei University Research Fund ( $\mathrm{TH}$ ) and the Vehicle Racing Commemorative Foundation (TH and HT).

\section{Disclosure}

The authors report no conflicts of interest in this work. 


\section{References}

1. Klein R, Peto T, Bird A, Vannewkirk MR. The epidemiology of age-related macular degeneration. Am J Ophthalmol. 2004;137(3):486-495.

2. Oshima Y, Ishibashi T, Murata T, Tahara Y, Kiyohara Y, Kubota T. Prevalence of age related maculopathy in a representative Japanese population: the Hisayama study. Br J Ophthalmol. 2001;85(10): 1153-1157.

3. Yasuda M, Kiyohara Y, Hata Y, et al. Nine-year incidence and risk factors for age-related macular degeneration in a defined Japanese population the Hisayama study. Ophthalmology. 2009;116(11):2135-2140.

4. Maruko I, Iida T, Saito M, Nagayama D, Saito K. Clinical characteristics of exudative age-related macular degeneration in Japanese patients. Am J Ophthalmol. 2007;144(1):15-22.

5. de Jong PT. Age-related macular degeneration. $N$ Engl J Med. 2006;355(14):1474-1485.

6. Klein RJ, Zeiss C, Chew EY, et al. Complement factor H polymorphism in age-related macular degeneration. Science. 2005;308(5720):385-389.

7. Haines JL, Hauser MA, Schmidt S, et al. Complement factor H variant increases the risk of age-related macular degeneration. Science. 2005;308(5720):419-421.

8. Edwards AO, Ritter R 3rd, Abel KJ, Manning A, Panhuysen C, Farrer LA. Complement factor H polymorphism and age-related macular degeneration. Science. 2005;308(5720):421-424.

9. Maller J, George S, Purcell S, et al. Common variation in three genes, including a noncoding variant in $\mathrm{CFH}$, strongly influences risk of agerelated macular degeneration. Nat Genet. 2006;38(9):1055-1059.

10. Li M, Atmaca-Sonmez P, Othman M, et al. CFH haplotypes without the $\mathrm{Y} 402 \mathrm{H}$ coding variant show strong association with susceptibility to age-related macular degeneration. Nat Genet. 2006;38(9):1049-1054.

11. Hughes AE, Orr N, Esfandiary H, Diaz-Torres M, Goodship T, Chakravarthy U. A common CFH haplotype, with deletion of CFHR1 and CFHR3, is associated with lower risk of age-related macular degeneration. Nat Genet. 2006;38(10):1173-1177.

12. Dewan A, Liu M, Hartman S, et al. HTRA1 promoter polymorphism in wet age-related macular degener ation. Science. 2006;314(5801):989-992.

13. Yang Z, Camp NJ, Sun H, et al. A variant of the HTRA1 gene increases susceptibility to age-related macular degeneration. Science. 2006;314(5801):992-993.

14. Fritsche LG, Loenhardt T, Janssen A, et al. Age-related macular degeneration is associated with an unstable ARMS2 (LOC387715) mRNA. Nat Genet. 2008;40(7):892-896.

15. Kanda A, Chen W, Othman M, et al. A variant of mitochondrial protein LOC387715/ARMS2, not HTRA1, is strongly associated with agerelated macular degeneration. Proc Natl Acad Sci USA. 2007;104(41): 16227-16232.

16. Spencer KL, Olson LM, Anderson BM, et al. C3 R102G polymorphism increases risk of age-related macular degeneration. Hum Mol Genet. 2008;17(12):1821-1824.

17. Edwards AO, Fridley BL, James KM, Sharma AK, Cunningham JM, Tosakulwong N. Evaluation of clustering and genotype distribution for replication in genome wide association studies: the age-related eye disease study. PLoS One. 2008;3(11):e3813.

18. Chen LJ, Liu DT, Tam PO, et al. Association of complement factor $\mathrm{H}$ polymorphisms with exudative age-related macular degeneration. Mol Vis. 2006;12:1536-1542.

19. Mori K, Gehlbach PL, Kabasawa S, et al. Coding and noncoding variants in the $\mathrm{CFH}$ gene and cigarette smoking influence the risk of age-related macular degeneration in a Japanese population. Invest Ophthalmol Vis Sci. 2007;48(11):5315-5319.

20. Wegscheider BJ, Weger M, Renner W, et al. Association of complement factor $\mathrm{H} \mathrm{Y} 402 \mathrm{H}$ gene polymorphism with different subtypes of exudative age-related macular degeneration. Ophthalmology. 2007;114(4): 738-742.

21. Kim NR, Kang JH, Kwon OW, Lee SJ, Oh JH, Chin HS. Association between complement factor $\mathrm{H}$ gene polymorphisms and neovascular age-related macular degeneration in Koreans. Invest Ophthalmol Vis Sci. 2008;49(5):2071-2076.
22. Ng TK, Chen LJ, Liu DT, et al. Multiple gene polymorphisms in the complement factor $\mathrm{h}$ gene are associated with exudative age-related macular degeneration in chinese. Invest Ophthalmol Vis Sci. 2008;49(8): 3312-3317.

23. Lee KY, Vithana EN, Mathur R, et al. Association analysis of $\mathrm{CFH}$, $\mathrm{C} 2, \mathrm{BF}$, and HTRA1 gene polymorphisms in Chinese patients with polypoidal choroidal vasculopathy. Invest Ophthalmol Vis Sci. 2008; 49(6):2613-2619.

24. Kondo N, Honda S, Kuno S, Negi A. Coding variant I62V in the complement factor $\mathrm{H}$ gene is strongly associated with polypoidal choroidal vasculopathy. Ophthalmology. 2009;116(2):304-310.

25. Goto A, Akahori M, Okamoto H, et al. Genetic analysis of typical wet-type age-related macular degeneration and polypoidal choroidal vasculopathy in Japanese population. J Ocul Biol Dis Infor. 2009;2(4): 164-175.

26. Hayashi H, Yamashiro K, Gotoh N, et al. CFH and ARMS2 variations in age-related macular degeneration, polypoidal choroidal vasculopathy, and retinal angiomatous proliferation. Invest Ophthalmol Vis Sci. 2010;51(11):5914-5919.

27. Tanaka K, Nakayama T, Yuzawa M, et al. Analysis of candidate genes for age-related macular degeneration subtypes in the Japanese population. Mol Vis. 2011;17:2751-2758.

28. Pei XT, Li XX, Bao YZ, et al. Association of c3 gene polymorphisms with neovascular age-related macular degeneration in a Chinese population. Curr Eye Res. 2009;34(8):615-622.

29. Yannuzzi LA, Negrao S, Iida T, et al. Retinal angiomatous proliferation in age-related macular degeneration. Retina. 2001;21(5):416-434.

30. Gass JD. Biomicroscopic and histopathologic considerations regarding the feasibility of surgical excision of subfoveal neovascular membranes. Am J Ophthalmol. 1994;118(3):285-298.

31. Freund KB, Ho IV, Barbazetto IA, et al. Type 3 neovascularization: the expanded spectrum of retinal angiomatous proliferation. Retina. 2008;28(2):201-211.

32. Cohen SY, Creuzot-Garcher C, Darmon J, et al. Types of choroidal neovascularisation in newly diagnosed exudative age-related macular degeneration. Br J Ophthalmol. 2007;91(9):1173-1176.

33. Viola F, Massacesi A, Orzalesi N, Ratiglia R, Staurenghi G. Retinal angiomatous proliferation: natural history and progression of visual loss. Retina. 2009;29(6):732-739.

34. Slakter JS, Yannuzzi LA, Schneider U, et al. Retinal choroidal anastomoses and occult choroidal neovascularization in age-related macular degeneration. Ophthalmology. 2000;107(4):742-753.

35. Kuroiwa S, Arai J, Gaun S, Iida T, Yoshimura N. Rapidly progressive scar formation after transpupillary thermotherapy in retinal angiomatous proliferation. Retina. 2003;23(3):417-420.

36. Boscia F, Furino C, Sborgia L, Reibaldi M, Sborgia C. Photodynamic therapy for retinal angiomatous proliferations and pigment epithelium detachment. Am J Ophthalmol. 2004;138(6):1077-1079.

37. Bottoni F, Massacesi A, Cigada M, Viola F, Musicco I, Staurenghi G. Treatment of retinal angiomatous proliferation in age-related macular degeneration: a series of 104 cases of retinal angiomatous proliferation. Arch Ophthalmol. 2005;123(12):1644-1650.

38. Sakimoto S, Gomi F, Sakaguchi H, Tano Y. Recurrent retinal angiomatous proliferation after surgical ablation. Am J Ophthalmol. 2005;139(5):917-918.

39. Shiragami C, Iida T, Nagayama D, Baba T, Shiraga F. Recurrence after surgical ablation for retinal angiomatous proliferation. Retina. 2007;27(2):198-203.

40. Silva RM, Cachulo ML, Figueira J, de Abreu JR, Cunha-Vaz JG. Chorioretinal anastomosis and photodynamic therapy: a two-year follow-up study. Graefes Arch Clin Exp Ophthalmol. 2007;245(8): 1131-1139.

41. Mullins RF, Russell SR, Anderson DH, Hageman GS. Drusen associated with aging and age-related macular degeneration contain proteins common to extracellular deposits associated with atherosclerosis, elastosis, amyloidosis, and dense deposit disease. FASEB J. 2000;14(7): $835-846$. 
42. Johnson LV, Leitner WP, Staples MK, Anderson DH. Complement activation and inflammatory processes in Drusen formation and age related macular degeneration. Exp Eye Res. 2001;73(6): 887-896.

43. Klein R, Davis MD, Magli YL, Segal P, Klein BE, Hubbard L. The Wisconsin age-related maculopathy grading system. Ophthalmology. 1991;98(7):1128-1134.

44. Cohen SY, Dubois L, Tadayoni R, Delahaye-Mazza C, Debibie C, Quentel G. Prevalence of reticular pseudodrusen in age-related macular degeneration with newly diagnosed choroidal neovascularisation. $\mathrm{Br} \mathrm{J}$ Ophthalmol. 2007;91(3):354-359.
45. Ooto S, Ellabban AA, Ueda-Arakawa N, et al. Reduction of retinal sensitivity in eyes with reticular pseudodrusen. Am J Ophthalmol. 2013;156(6):1184-1191.

46. Querques G, Massamba N, Srour M, Boulanger E, Georges A, Souied EH. Impact of reticular pseudodrusen on macular function. Retina. July 9, 2013. [Epub ahead of print.]

47. Ueda-Arakawa N, Ooto S, Nakata I, et al. Prevalence and genomic association of reticular pseudodrusen in age-related macular degeneration. Am J Ophthalmol. 2013;155(2):260-269.

48. Lee MY, Yoon J, Ham DI. Clinical characteristics of reticular pseudodrusen in Korean patients. Am J Ophthalmol. 2012;153(3):530-535.
Clinical Ophthalmology

\section{Publish your work in this journal}

Clinical Ophthalmology is an international, peer-reviewed journal covering all subspecialties within ophthalmology. Key topics include: Optometry; Visual science; Pharmacology and drug therapy in eye diseases; Basic Sciences; Primary and Secondary eye care; Patient Safety and Quality of Care Improvements. This journal is indexed on

\section{Dovepress}

PubMed Central and CAS, and is the official journal of The Society of Clinical Ophthalmology (SCO). The manuscript management system is completely online and includes a very quick and fair peer-review system, which is all easy to use. Visit http://www.dovepress.com/ testimonials.php to read real quotes from published authors. 